\title{
Word naming times and psycholinguistic norms for Italian nouns
}

\author{
LAURA BARCA \\ Institute for Cognitive Sciences and Technologies, National Research Council (CNR), Rome, Italy \\ and University of Rome "La Sapienza," Rome, Italy \\ CRISTINA BURANI \\ Institute for Cognitive Sciences and Technologies, National Research Council (CNR), Rome, Italy \\ and \\ LISA S. ARDUINO \\ Institute for Cognitive Sciences and Technologies, National Research Council (CNR), Rome, Italy \\ and University of Milan-Bicocca, Milan, Italy
}

\begin{abstract}
The present study describes normative measures for 626 Italian simple nouns. The database (LEXVAR. XLS) is freely available for down-loading on the Web site http://wwwistc.ip.rm.cnr.it/material/ database/. For each of the 626 nouns, values for the following variables are reported: age of acquisition, familiarity, imageability, concreteness, adult written frequency, child written frequency, adult spoken frequency, number of orthographic neighbors, mean bigram frequency, length in syllables, and length in letters. A classification of lexical stress and of the type of word-initial phoneme is also provided. The intercorrelations among the variables, a factor analysis, and the effects of variables and of the extracted factors on word naming are reported. Naming latencies were affected primarily by a factor including word length and neighborhood size and by a word frequency factor. Neither a semantic factor including imageability, concreteness, and age of acquisition nor a factor defined by mean bigram frequency had significant effects on pronunciation times. These results hold for a language with shallow orthography, like Italian, for which lexical nonsemantic properties have been shown to affect reading aloud. These norms are useful in a variety of research areas involving the manipulation and control of stimulus attributes.
\end{abstract}

Word recognition processes and speech production have been shown to be affected by many lexical and sublexical variables, both in adults and children and in unimpaired and impaired language conditions.

A few normative data are available for Italian, but they usually consider only one variable at a time (Cornoldi, 1974; Miceli, Benveniste, Zannino, \& Capasso, 2000; Roncato, 1974) or focus exclusively on the orthographic, phonological, morphological, and grammatical characteristics of

For this work, we made recourse to the kindness and patience of many persons. Catriona Morrison made available the English instructions for the ratings of age of acquisition, and Margherita Orsolini gave us suggestions concerning their adaptation to Italian. Harald Baayen created the program for calculating bigram frequency. Dario Salmaso collaborated in the creation of the Web site that includes the database. Teresa Gloria Scalisi and Elizabeth Bates provided valuable statistical advice. Caterina Silveri, Antonella Cappa, Erminio Capitani, Marcella Laiacona, Claudio Luzzatti, Elizabeth Bates, and Simona D'Amico discussed with us different stages of the work. Alessandro Laudanna and Stefania Marcolini gave us useful comments on the first draft of the manuscript. We are also indebted to Joan Gay Snodgrass and to two anonymous reviewers for useful comments on an earlier version of the paper. We give all of them our sincere acknowledgments. Correspondence concerning this article should be addressed to C. Burani, Istituto di Scienze e Tecnologie della Cognizione ISTC-CNR, Viale Marx, 15, 00137 Roma, Italy (e-mail: burani@ip.rm.cnr.it). words (see Thornton, Iacobini, \& Burani, 1994, 1997). Recently, normative data for Italian have been reported, referring to variables that affect picture naming, such as name agreement, object familiarity (FAM), and age of acquisition (AoA; Dell'Acqua, Lotto, \& Job, 2000; Nisi, Longoni, \& Snodgrass, 2000).

In the present study, values referring to a variety of lexical and sublexical variables for 626 Italian nouns are reported. The variables have been selected from among those shown to affect single-word tasks, such as singleword reading aloud and lexical decision. The present lexical database, available on the Web site http://wwwistc. ip.rm.cnr.it/material/database/ (LEXVAR.XLS, Excel 5.0 ), is useful for research into lexical processing and provides an instrument for the study, the assessment, and the rehabilitation of Italian patients with lexical-processing disorders.

\section{Material}

The pool of words, selected from an adult written frequency (Adult WrtFQ) count (Istituto di Linguistica Computazionale, 1989), with the constraints of being morphologically simple, not ambiguous for grammatical category or for meaning, and 4-9 letters long, was sufficiently heterogeneous to allow considerable variation on each of the 
independent measures. Six hundred and twenty-six Italian singular nouns were selected.

\section{Database}

For each of the 626 Italian nouns, values for the following variables are reported: AoA, word familiarity, imageability (IMAG), concreteness (CONC), adult written word frequency (Adult WrtFQ), child written (ChildWrt) word frequency, subdivided into total frequency values (TotFQ), frequency of the words read by children (ChildWrt CompFQ), and frequency of the words written by children (Child Wrt Prod FQ), adult spoken word frequency (Adult SpkFQ), number of orthographic neighbors (NSIZE), mean bigram frequency (BIGR), word length in syllables (SYL), and word length in letters (LET). Three nonnumerical fields are included, reporting the type of lexical stress (either on the penultimate syllable [p] or on the antepenultimate [ap]), the type of word initial phoneme, classified for voiced versus voiceless (PHON:VOICE) and for manner of articulation (PHON:MANN).

Raw values for the numerical variables are reported. Only BIGR frequency values are transformed on the basis of the natural logarithm. For the first four variables (i.e., AoA, FAM, IMAG, and CONC), which were obtained from empirical ratings given by Italian university students (see below), standard deviations ( $S D$ s) are also reported.

For each noun, the mean pronunciation time, as drawn from a word-naming experiment conducted on 30 Italian participants (see below), is also reported. The English translation for each Italian word is included.

\section{Variables}

Although most variables in the list require little explanation, a few qualifying remarks are in order.

$A o A$ is defined as the estimated age at which a word and its meaning were first learned, either in the auditory or in the written modality. Several studies have shown that this variable, obtained from empirical ratings, may be a strong predictor of adult performance in several tasks such as auditory and visual lexical decision, word naming, picture naming, object naming, and face recognition (Brown \& Watson, 1987; Carroll \& White, 1973; Colombo \& Burani, 2002; Ellis \& Lambon Ralph, 2000; Ellis \& Morrison, 1998; Gerhand \& Barry, 1999; Moore \& Valentine, 1998; Morrison \& Ellis, 1995; Turner, Valentine, \& Ellis, 1998), in that early acquired words are recognized and read faster than late acquired words, and faces that are early "acquired" and recognized in childhood are recognized faster than late acquired faces.

$F A M$ is defined as the estimated frequency of occurrence of a word, in written or spoken form, in the raters' own daily lives or in other people's daily lives (Connine, Mullennix, Shernoff, \& Yelen, 1990; Gernsbacher, 1984; Noble, 1953).

$I M A G$ is defined as the ease and speed with which a target word evokes a mental image, a visual representation, a sound, or any other sensory experience (Cornoldi, 1974; Paivio, Yuille, \& Madigan, 1968; Roncato, 1974). The effects of IMAG on lexical processing are controversial (for a review, see Balota, Ferraro, \& Connor, 1990). Several studies have shown that the effects of this variable on word naming are restricted to low-frequency irregular words (Cortese, Simpson, \& Woolsey, 1997; Strain, Patterson, \& Seidenberg, 1995; Zevin \& Balota, 2000) or to poor readers (V. Coltheart, Laxon, \& Keating, 1988; Strain \& Herdman, 1999).

CONC is defined as the property of words of referring to objects, animate beings, actions, or materials that can be experienced directly by the senses (Paivio et al., 1968; Roncato, 1974). CONC has been found to positively affect lexical decision (Bleasdale, 1987), mainly to low-frequency words (James, 1975).

Values referring to AoA, FAM, IMAG and CONC were obtained from subjective ratings (on a 7-point scale) given by 176 participants. All the raters were native speakers of Italian between 20 and 30 years of age, students at one of several universities in Rome. Each of the four ratings was obtained from 44 participants, half male and half female. None of the students participated in more than one rating. The 626 nouns were printed in a booklet and presented to the participants in different randomization orders. There were three different randomizations for each type of rating. In addition, sheets of the booklet were also presented in different orders.

An English translation of the rating instructions is given in the Appendix. The instructions were drawn from the literature. The instructions regarding AoA were adapted from those used by, among others, Morrison and Ellis (1995) for studies of English, and the instructions for IMAG and CONC were adapted from Paivio et al. (1968). Finally, the instructions for FAM were adapted from those used for other languages (see, e.g., Connine et al., 1990; Gernsbacher, 1984; Noble, 1953). ${ }^{1}$

Adult WrtFQ was taken from a frequency count based on a corpus of $1,500,000$ words in contemporary written Italian texts (Istituto di Linguistica Computazionale, 1989). Although the role of word frequency in influencing the speed and accuracy with which a word is recognized in lexical decision has been well established, results on word naming are more controversial (Balota \& Chumbley, 1990; Frost, 1994; Gerhand \& Barry, 1998; Monsell, Doyle, \& Haggard, 1989). However, frequency effects have been reported also on Italian word naming (Burani, Marcolini, \& Stella, 2002; Colombo, 1992).

ChildWrt word frequency was extracted from the Lessico elementare (Elementary Lexicon) by Marconi, Ott, Pesenti, Ratti, and Tavella, (1993) and was subdivided into total frequency values (TotFQ), frequency of the words occurring in the child comprehension lexicon (i.e., in texts that are read by children in the elementary grades; ChildWrt CompFQ), and frequency of the child written production lexicon (i.e., words written by children in the same grades; ChildWrt ProdFQ). The corpus includes a total of 1,000,000 word tokens: 500,000 word tokens were adopted from readers, fairy tales, school newspapers, comic books, and textbooks directed to children between the first and fifth grades; another 500,000 tokens were 
taken from essays written by first to fifth grade children. ChildWrt CompFQ is thus similar to the frequency measure provided by Carroll, Davies, and Richman (1971) for American English on a larger corpus and for third to ninth graders. ChildWrt ProdFQ is closer to frequency counts based mainly on child written productions, like Rinsland's (1945) and Santiago, Justicia, Palma, Huertas, and Gutiérrez's (1996) for English and Spanish, respectively.

Adult SpkFQ was taken from the frequency count by De Mauro, Mancini, Vedovelli, and Voghera (1993), based on a corpus of 500,000 words from samples of contemporary spoken Italian. The influence of spoken word frequency on word-naming and other lexical tasks has not been very much investigated. However, this frequency measure might have some effect on the production component of several tasks (Brown, 1984; Brown \& Watson, 1987).

NSIZE corresponds to the number of words that differ by one letter with respect to a target word while preserving the identity and position of the other letters (M. Coltheart, Davelaar, Jonasson, \& Besner, 1977; for a review of the effects of NSIZE on word and pseudoword processing, see Andrews, 1997, and Arduino \& Burani, 2002). NSIZE values were taken from the database presented by Baldi and Traficante (2001) and have been adjusted to exclude word neighbors that are highly unfamiliar.

$B I G R$ is a measure of transitional orthographic frequency - that is, the frequency with which adjacent pairs of letters (bigrams) occur in printed texts. Its effects on lexical processing are controversial (see, e.g., Andrews, 1992; Gernsbacher, 1984). BIGR might be calculated as length-specific positional-that is, as the frequency with which a particular pair of letters occurs in a specified position of words of a given length. In the present database, word BIGR is reported by calculating the frequency of two adjacent letters in any word position. Word BIGRs were calculated on the written frequency count by the Istituto di Linguistica Computazionale (1989).

$S Y L$ was automatically extracted from the database of Thornton et al. (1994, 1997). This variable has been shown to influence word recognition (Spoehr \& Smith, 1973), although its role in reading aloud seems limited to lowfrequency words (Jared \& Seidenberg, 1990). ${ }^{2}$

LET corresponds to the number of letters included in a word. (For the investigation of word length effects on reading, see, e.g., Burani, Barca, \& Arduino, 2002, and Weekes, 1997, for Italian and English, respectively.)

Lexical stress. The very great majority of Italian bisyllable words have stress on the penultimate syllable. In the database, all bisyllables have stress on the penultimate syllable. Three-syllable words are in most cases stressed on the penultimate syllable; however, a smaller percentage of Italian three-syllable words (estimated as around 15\%, a percentage respected in the database) bear stress on the antepenultimate. The few four-syllable words in the database are stressed either on the penultimate or on the antepenultimate. There is only one five-syllable word, stressed on the penultimate syllable. In Italian words with three or more syllables, stress is the only aspect of pronunciation not fully predictable by rule but requiring lexical look-up. Hence, the consequences of stress on lexical reading need to be taken into account (see, e.g., Colombo, 1992; Colombo \& Tabossi, 1992; Tabossi \& Laghi, 1992).

Type of word-initial phoneme, classified for PHON: VOICE and for PHON:MANN. The classification is based on the standard pronunciation as reported in a dictionary of Italian (Zingarelli, 1985).

Table 1 lists the numerical variables included in the database, and descriptive statistics for each variable are also presented.

\section{Comparison of This Database With the MRC Psycholinguistic Database for English}

The present Italian database could be usefully compared with a similar tool, the MRC psycholinguistic database, which is widely used for English and was explicitly devised for researchers in psycholinguistics, and the neuropsychology of language and for computer scientists in general. The MRC psycholinguistic database, both in Version 1.00 (M. Coltheart, 1981) and in Version 2.00, available from http://www.psy.uwa.edu.au/MRCDataBase/ mrc2.html, includes a considerably larger number of entries $(98,538$ words in Version 1.00, 150,837 words in Version 2.00) relative to the present database. However, the general structure of the two databases is similar, being focused on the same word properties as those that are known to affect lexical processing, although information about every property is not available for every one of the MRC words.

Although the two databases share basic assumptions, some choices for inclusion of variables are in part different. Whereas the MRC psycholinguistic database reports words belonging to all the grammatical categories, including morphologically complex words and proper names, as well as simple nouns, the present database is limited to simple unambiguous nouns. Consequently, a number of properties that are included in the MRC dictionary file from the database, having to do with part of speech and morphological structure, are obviously lacking in the Italian database. The two databases have in common information on such word properties as number of letters, number of syllables, and stress pattern. Number of phonemes is given only for the English database. However, the Italian database also includes two variables that are not present in the MRC psycholinguistic database, namely NSIZE (the number of words differing by one letter with respect to the target word) and BIGR (see above). With respect to frequency values, both the MRC psycholinguistic database and the present database include values of written and spoken frequency. For English, as well as for Italian, measures from two different written frequency counts are provided. However, the Italian values of child written frequency are more recent and are subdivided into two measures, corresponding to the frequency of words read by children and of words written by children.

With respect to the word properties that were drawn from subjective ratings, four are in common in the two 
Table 1

Descriptive Statistics on Independent Variables

\begin{tabular}{llrrrc}
\hline \multicolumn{1}{c}{ Variable } & \multicolumn{1}{c}{ Code } & Mean & SD & Min & Max \\
\hline Age of acquisition & AoA & 3.69 & 1.17 & 1.10 & 6.77 \\
Familiarity & FAM & 6.04 & 0.73 & 3.40 & 7.00 \\
Imageability & IMAG & 5.00 & 1.13 & 1.88 & 6.68 \\
Concreteness & CONC & 5.42 & 1.12 & 2.04 & 7.00 \\
Adult written word frequency & Adult WrtFQ & 81.94 & 191.41 & 1 & 2,253 \\
Child written word frequency, total & ChildWrt TotFQ & 107.26 & 290.71 & 0 & 3,584 \\
Frequency of words written by children & ChildWrt CompFQ & 44.61 & 94.3 & 0 & 873 \\
Frequency of words read by children & ChildWrt ProdFQ & 62.77 & 209.8 & 0 & 2,711 \\
Adult spoken word frequency & Adult SpkFQ & 14.78 & 41.93 & 0 & 471 \\
Number of orthographic neighbors & NSIZE & 1.16 & 1.79 & 0 & 13 \\
Mean bigram frequency & BIGR & 10.82 & 0.39 & 8.81 & 11.68 \\
Length in syllables & SYL & 2.7 & 0.65 & 2 & 5 \\
Length in letters & LET & 6.3 & 1.55 & 4 & 9 \\
\hline
\end{tabular}

Note-AoA, FAM, IMAG, and CONC are given as 7-point subjective ratings; Adult WrtFQ is taken from a total of 1.5 million occurrences, ChildWrt TotFQ from 1 million occurrences, ChildWrt CompFQ from 500,000 occurrences, ChildWrt ProdFQ from 500,000 occurrences, Adult SpkFQ from 500,000 occurrences, and BIGR from 1.5 million occurrences. Bigram frequency values are transformed on the basis of the natural logarithm. For a detailed description of the variables, see the text.

databases-namely, FAM, AoA, IMAG, and CONC. They have been collected by using similar instructions. However, the values for English were derived from merging different sets of existing norms, whereas the values for the Italian nouns were collected for the purposes of this database. The Italian database does not include meaningfulness ratings, which are, by contrast, included in the MRC psycholinguistic database.

Finally, whereas the MRC psycholinguisticdatabase provides phonetic transcriptions of the words, the Italian database includes phonetic categorizations of the word's initial phonemes, which have been shown to be specifically effective in triggering the voice key in the reading of words aloud.

\section{Correlations Among Variables}

The matrix of correlations (Pearson correlations) among mean values of the numerical variables for the 626 Italian nouns is reported in Table 2. All frequency indices, including NSIZE, were log transformed.
Several comments are in order. The first comment is related to the substantial degree of collinearity among these variables (substantially intercorrelated variables). A similar pattern of multicollinearity has been described in studies of English (see, e.g., Gilhooly \& Logie, 1980, 1981, 1982; Morrison \& Ellis, 2000; Rubin, 1980; Whaley, 1978), as well as of other languages, such as, for example, Spanish (Cuetos, Ellis, \& Alvarez, 1999) and Japanese (Yamada, Takashima, \& Yamazaki, 1998; Yamazaki, Ellis, Morrison, \& Lambon Ralph, 1997). AoA has the highest correlations with all the other variables. Specifically, AoA has negative correlations with FAM $(-.80)$, IMAG $(-.70)$, and child written frequency $(-.67)$, with both ChildWrt CompFQ (-.62) and ChildWrt ProdFQ (-.71), suggesting that early acquired words tend to be considered as highly familiar and very imageable and that they also occur frequently in texts both written and read by children.

The frequency indexes were all highly intercorrelated. Furthermore, all the frequency indexes were correlated

Table 2

Correlations Among Variables for 626 Words

\begin{tabular}{|c|c|c|c|c|c|c|c|c|c|c|c|c|}
\hline Variable & AoA & FAM & IMAG & CONC & $\begin{array}{c}\text { Adult } \\
\text { WrtFQ }\end{array}$ & $\begin{array}{c}\text { ChildWrt } \\
\text { TotFQ }\end{array}$ & $\begin{array}{l}\text { ChildWrt } \\
\text { CompFQ }\end{array}$ & $\begin{array}{c}\text { ChildWrt } \\
\text { ProdFQ }\end{array}$ & $\begin{array}{l}\text { Adult } \\
\text { SpkFQ }\end{array}$ & NSIZE & BIGR & SYL \\
\hline FAM & -.80 & & & & & & & & & & & \\
\hline IMAG & -.70 & .56 & & & & & & & & & & \\
\hline $\mathrm{CONC}$ & -.38 & .18 & .67 & & & & & & & & & \\
\hline Adult WrtFQ & -.37 & .52 & n.s. & -.19 & & & & & & & & \\
\hline ChildWrt TotFQ & -.67 & .71 & .30 & n.s. & .70 & & & & & & & \\
\hline ChildWrt CompFQ & -.62 & .67 & .26 & n.s. & .71 & .97 & & & & & & \\
\hline ChildWrt ProdFQ & -.71 & .70 & .34 & n.s. & .68 & .94 & .87 & & & & & \\
\hline Adult SpkFQ & -.27 & .41 & n.s. & -.21 & .70 & .58 & .59 & .58 & & & & \\
\hline NSIZE & -.20 & n.s. & n.s. & n.s. & .16 & .17 & .18 & .18 & .10 & & & \\
\hline BIGR & n.s. & .11 & n.s. & n.s. & .20 & .14 & .13 & .14 & .16 & .24 & & \\
\hline SYL & .22 & -.12 & n.s. & n.s. & -.22 & -.26 & -.26 & -.27 & .11 & -.54 & n.s. & \\
\hline LET & .20 & n.s. & n.s. & n.s. & -.19 & -.22 & -.23 & -.22 & .11 & -.63 & n.s. & .79 \\
\hline
\end{tabular}

Note-AoA, age of acquisition; FAM, familiarity; IMAG, imageability; CONC, concreteness; AdultWrtFQ, adult written word frequency; ChildWrt TotFQ, child written word frequency total; ChidWrt CompFQ, frequency of words read by children; ChildWrt ProdFQ, frequency of words written by children; Adult SpkFQ, adult spoken word frequency; NSIZE, number of orthographic neighbors; BIGR, mean bigram frequency; SYL, length in syllables; LET, length in letters. $p<.01$. 
with rated FAM, indicating that words with highfrequency values in the adult and child written lexicon and in the adult spoken lexicon are also very common in daily life. Nevertheless, frequency indexes and FAM have different correlations with other variables, such as IMAG. Adult WrtFQ and Adult SpkFQ have nonsignificant correlations with IMAG, whereas all the ChildWrt word frequency measures, as well as FAM, have significant correlations with word IMAG. The latter correlations suggest that adult frequency measures and rated FAM may refer, at least in part, to different characteristics of words. The latter pattern of correlations as a whole is very similar to the patterns of correlations that have been reported for other languages (see above).

IMAG and CONC are unsurprisingly highly correlated (.67). IMAG and CONC could be considered to be variables that refer to similar word properties. However, our analysis indicates that these two variables do not measure the same semantic attribute of verbal material but may relate to different word and concept characteristics (see also Richardson, 1975). This is also indicated by the fact that IMAG and CONC differ in their pattern of correlations with other variables, such as frequency, AoA, and FAM. Specifically, whereas CONC has significant negative, although small, correlations with adult frequency measures (with more frequent words in adult language tending to be less concrete), IMAG has much higher and highly significant correlations with FAM and with all child frequency measures, including AoA. When IMAG is considered, the results of our correlational analysis, conducted on a word sample not limited to depictable nouns, are more similar to those that have been obtained on word samples that not only included object names, but also had a wider IMAG range, including abstract words as well (see, e.g., Gilhooly \& Logie, 1980, 1982; Rubin, 1980; Whaley, 1978). By contrast, the correlations of IMAG with other variables are necessarily limited when word samples that refer to entities that should be easily depicted for picture naming are used.

The different ChildWrt word frequency measures are highly intercorrelated and, as was already noted above, have substantially the same correlations with other variables. However, words that are very frequent in the texts written by children themselves (ChildWrt ProdFQ) have higher correlations with AoA (-.71) and with IMAG (.34), with respect to words that are very frequent in the texts read by children (ChildWrt CompFQ).

NSIZE, BIGR, SYL, and LET do not have high correlations with other variables. LET and SYL are highly intercorrelated (.79) and have very similar correlations with other variables. Moreover, LET, SYL, and NSIZE are highly intercorrelated. Not surprisingly, shorter words and words with a low number of syllables have a greater number of orthographic neighbors (NSIZE) than do longer words and words with a higher number of syllables. For adopting a length measure based on single letters, the correlation of length with NSIZE is obviously higher (-.64) than the correlation found when length had been calcu- lated as number of phonemes (see, e.g., Morrison \& Ellis, 2000; Weekes, 1997). Furthermore, NSIZE tends also to correlate more highly with BIGR than with word frequency measures (see also Frauenfelder, Baayen, Hellwig, \& Schreuder, 1993, for both English and Dutch).

\section{Factor Analysis}

In order to further clarify the above results by reducing the correlation matrix to an interpretable summary, the numerical variables were submitted to a factor analysis (principal components analysis) with orthogonal (vari$\max$ ) rotation. The only variable removed from factor analysis was ChildWrt TotFQ, which is formed by summing ChildWrt CompFQ and ChildWrt ProdFQ. The standard criterion of eigenvalues greater than or equal to one was used to determine the number of factors. Variables that were highly intercorrelated consequently loaded on a common factor.

In Table 3, the factor solution is illustrated. The numbers reported in the table refer to the correlations, or loadings, among the variables and the factors.

Four factors were extracted: (1) a word frequency factor for which several frequency measures showed high loadings; these measures were Adult WrtFQ, ChildWrt CompFQ, ChildWrt ProdFQ, Adult SpkFQ, and FAM; (2) a semantic factor, for which the following variables showed high loadings: AoA, IMAG, and CONC; (3) a length-NSIZE factor, which included LET, SYL, and NSIZE; (4) a bigram frequency factor related to an orthographic measure of transitional probability, for which only BIGR showed a high loading. This factor solution is very similar to other factor analyses conducted for English (see, e.g., Rubin, 1980; Whaley, 1978). The four factors together account for $81.8 \%$ of the common variance, and the variance accounted for by each factor is shown in Table 3. When Table 3 is examined, it can be seen that the factors are quite clean, with many variables loading on only one factor. With the exception of AoA and FAM, there is little overlap for most variables.

It is worth making two main observations. First, both AoA and FAM variables cannot be explained in terms of a single factor but need some combination of factors. The interesting finding that AoA and FAM loaded on both the word frequency factor and the semantic factor allows one to dissociate two aspects of both AoA and FAM that tend to be confounded: frequency-related variance and variance related to semantic factors such as IMAG and CONC and to AoA (for similar results and interpretation, see Bates, Burani, D’Amico, \& Barca, 2001; see also Paivio, Clark, Digdon, \& Bons, 1989; Rubin, 1980; Whaley, 1978).

Second, the emergence of a factor (Factor 4) in which BIGR alone is represented points to the dissociability of this variable from other variables potentially correlated to it (namely, NSIZE and word written frequency). Specifically, BIGR has its highest correlation with NSIZE (.24). As has already been noted by, for example, Andrews (1997) and Frauenfelder et al. (1993), words with higher BIGR tend to have a higher NSIZE. NSIZE is in fact the 
Table 3

Factor Loadings for Variables (626 Words)

\begin{tabular}{lcccc}
\hline \multicolumn{1}{c}{ Variables } & $\begin{array}{c}\text { Factor 1 } \\
\text { Word Frequency }\end{array}$ & $\begin{array}{c}\text { Factor } 2 \\
\text { Semantics }\end{array}$ & $\begin{array}{c}\text { Factor 3 } \\
\text { Length-NSIZE }\end{array}$ & $\begin{array}{c}\text { Factor } 4 \\
\text { Bigram Frequency }\end{array}$ \\
\hline AoA & -.58 & -.70 & -.13 & .02 \\
FAM & .73 & .51 & .00 & .01 \\
IMAG & .14 & .93 & .01 & .01 \\
CONC & -.18 & .83 & .06 & .03 \\
Adult WrtFQ & .86 & -.16 & .12 & .11 \\
ChildWrt CompFQ & .88 & .18 & .15 & .01 \\
ChildWrt ProdFQ & .87 & .27 & .15 & .01 \\
Adult SpkFQ & .80 & -.24 & .03 & .11 \\
NSIZE & .06 & .08 & .79 & .31 \\
BIGR & .12 & .02 & .05 & .96 \\
SYL & -.15 & -.04 & -.89 & .17 \\
LET & -.11 & -.01 & -.92 & .00 \\
\% Variance & 32.42 & 20.78 & 19.60 & 9.00 \\
\hline
\end{tabular}

Note-AoA, age of acquisition; FAM, familiarity; IMAG, imageability; CONC, concreteness; Adult WrtFQ, adult written word frequency; ChildWrt CompFQ, frequency of words read by children; ChildWrt ProdFQ, frequency of words written by children; Adult SpkFQ, adult spoken word frequency; NSIZE, number of orthographic neighbors; BIGR, mean bigram frequency; SYL, length in syllables; LET, length in letters.

only other variable that has some, although limited, loading in the BIGR factor. Nevertheless, the loading of NSIZE on the length factor is higher than its loading on the bigram frequency factor (see also Arduino \& Burani, 2002).

\section{WORD-NAMING EXPERIMENT}

The aim of the following experiment was to assess which factors turned out to be the best predictors of Italian adults' naming speed.

\section{Method}

Materials. All the 626 words were included in the experimental list. The list included $44 \%$ bisyllable words with predictable stress on the penultimate syllable and 56\% 3-4 syllable words for which lexical stress was less predictable by rule. Moreover, $15 \%$ of the words out of the total list had the less frequent stress on the antepenultimate syllable. This list composition highly favored lexical look-up for stress assignment, thus allowing lexical-semantic effects, if any, to manifest themselves in reading aloud (see Colombo \& Tabossi, 1992; Tabossi \& Laghi, 1992).

Participants and Procedure. Thirty students from Rome universities (15 males and 15 females), 20-30 years of age, participated in the experiment. None of them had participated in the AoA, FAM, IMAG, and CONC ratings. All were native speakers of Italian. The participants, tested individually, were asked to read aloud, as quickly and as accurately as possible, a series of words that would appear on the computer screen in front of them. Reaction times from word onset to the beginning of each vocalization were collected by a voice key connected to the computer, within the MEL Professional 2.0 experimental control shell. A microphone was connected to the voice key and to a tape recorder for registering the session.

The stimuli appeared in capital letters in the center of the computer screen, preceded by a 400-msec dot. They stayed on the computer screen until the participant made a verbal response, for a maximum of $1 \mathrm{sec}(1,000 \mathrm{msec})$. The experimenter took note of all the stimuli incorrectly pronounced, and these were eliminated from all subsequent analyses. There was an interstimulus interval of $1,500 \mathrm{msec}$ before the presentation of the next fixation dot.

The words were presented in six blocks of either 104 or 105 words each. The values of the variables were balanced for the different blocks. For each participant, the order of words within blocks was randomized differently. The order of block presentation also varied for each participant. The experiment was preceded by a brief practice session consisting of two blocks composed of 12 items each in different randomization orders.

\section{Results}

The stimuli with reaction times of less than $200 \mathrm{msec}$ were considered as missing data and accounted for about $0.02 \%$ of the total data points. Another $2.04 \%$ of the total data points, consisting of mispronunciations or latencies exceeding the deadline $(1,000 \mathrm{msec})$, were excluded from the analysis of naming latencies. The choice was made to limit the analysis of reaction times to the words not beginning with those particular initial phonemes that would trigger the voice key differentially, either more slowly or more rapidly, with respect to the others.

Several studies of English have indeed shown that the different word-initial phonemes affect voice key activation differently (see Morrison \& Ellis, 2000; Spieler \& Balota, 1997; Treiman, Mullennix, Bijeljac-Babic, \& RichmondWelty, 1995); thus, it was decided to control for these phonemic properties. We subdivided the sample of 626 words into five classes ranked according to each word's beginning phoneme (for a similar classification, see Balota \& Chumbley, 1985). The five ordered categories had words beginning with (1) voiceless stop consonants $(n=171),(2)$ voiced stop consonants $(n=73)$, (3) vowels or glides $(n=83)$, (4) liquid, nasal, labiodental fricatives $(n=192),(5)$ alveolar and postalveolar fricatives and affricates $(n=107)$. The rationale for these five categories was that words with beginning phonemes from the first four categories might be produced and might activate the voice key more quickly than did words that had a beginning phoneme from the latter category. Thus, we conducted a preliminary one-way analysis of variance (ANOVA) on the mean reaction times for these five categories. The results of the ANOVA showed a significant 
difference for the pronunciation latencies among the five groups $\left[F(1,621)=77.45, M S_{\mathrm{e}}=696.37, p<.001\right]$. Post hoc tests (based on both Newman-Keuls's and Duncans' tests) on paired categories showed that Group 5, which included alveolar and postalveolar fricatives and affricates as initial phonemes, was the only one significantly different from all the other groups, with slower mean naming times $(571 \mathrm{msec})$ with respect to the other groups, which had the following mean reaction times: (1) 533, (2) 532, (3) 515 , and (4) $520 \mathrm{msec}$. Thus, the words falling in Category 5 were dropped from the final analyses. Three other items were excluded from analysis for having reaction times more than $2.5 S D$ s above the mean on the entire list.

The final analyses considered 516 words. The overall mean reaction times, over items, was $525 \mathrm{msec}(S D=$ 24.7 , range $=474-597$ ).

Correlations among predictor variables and naming latencies. Pearson correlations among predictor variables and naming latencies are reported in Table 4.

A comparison between Table 2 and Table 4 shows that the correlations among independent variables are substantially the same when the experimentallist composed of 516 stimuli and the initial sample including 626 words are considered. With respect to the correlations among independent variables and naming latencies, the results indicated that LET and SYL are the variables that correlated the most with naming latency (.47 and .35 , respectively), so that shorter words and words with fewer syllables were pronounced faster than longer words and words with a higher number of syllables (for similar high correlations for languages such as English and Dutch, see, e.g., Gilhooly \& Logie, 1981; Hudson \& Bergman, 1985; Morrison \& Ellis, 2000).

ChildWrt CompFQ (-.33), ChildWrt ProdFQ (-.31), and Adult WrtFQ (-.29) were also highly correlated with mean reaction times, so that words that are very frequent in written form are read faster than unfrequent written words (the correlations between ChildWrt CompFQ and
ChildWrt ProdFQ and reaction time were even higher than the one between Adult WrtFQ and reaction time; see also Burani, Barca, \& Arduino, 2002, for further explorations).

Furthermore, the pronunciationlatencies for words with a large neighborhood, for early acquired words, and for high-familiarity words tend to be shorter than the latencies for words that have a small neighborhood, are late acquired and have low-familiarity values. A suggestion that can be drawn from this preliminary correlational analysis is that, for Italian, variables such as LET and SYL, NSIZE, child and adult written frequency, FAM, and AoA can be predictors of adults' performance in reading words aloud. This pattern of correlations and the substantial degree of colinearity among the various predictors are very consistent across different samples of items. Obviously, the clarification of the relative roles of each different variable requires either a multivariate approach, in which the contribution of each predictor can be compared when variance from overlapping variables is controlled, or experimental designs that vary the variables of interest while controlling for other variables (see Bates et al., 2001; Burani, Barca, \& Arduino, 2002).

Factor Analysis. To deal with the collinearity among predictors reported above, a principal components factor analysis with orthogonal(varimax) rotation was conducted, with the specific aim of reducing the number of variables to a more manageable, coherent, and distinct subset. This new factor analysis on the set of words submitted to naming can be inspected to assess whether the use of one of the two samples ( 626 vs. 516 words) may give rise to some differences. In Table 5, the results of the factor analysis on the 516 words are presented.

Four factors with eigenvalues greater than 1.0 emerged from this analysis. The four-factor solution is very stable across items. It proved to be substantially the same for the two samples (626 vs. 516): (1) a word frequency factor (Adult WrtFQ, the ChildWrt frequencies, Adult SpkFQ, and FAM); (2) a semantic factor (AoA, IMAG, and CONC);

Table 4

Correlations Among Predictor Variables and Naming Latencies (RT) for 516 Words

\begin{tabular}{|c|c|c|c|c|c|c|c|c|c|c|c|c|c|}
\hline & RT & AoA & FAM & IMAG & $\mathrm{CONC}$ & $\begin{array}{c}\text { Adult } \\
\text { WrtFQ }\end{array}$ & $\begin{array}{c}\text { ChildWrt } \\
\text { TotFQ }\end{array}$ & $\begin{array}{l}\text { ChildWrt } \\
\text { CompFQ }\end{array}$ & $\begin{array}{c}\text { ChildWrt } \\
\text { ProdFQ } \\
\end{array}$ & $\begin{array}{c}\text { Adult } \\
\text { SpkFQ }\end{array}$ & NSIZE & BIGR & SYL \\
\hline $\mathrm{AoA}$ & .25 & & & & & & & & & & & & \\
\hline FAM & -.26 & -.80 & & & & & & & & & & & \\
\hline IMAG & -.13 & -.70 & .57 & & & & & & & & & & \\
\hline CONC & n.s. & -.39 & .21 & .68 & & & & & & & & & \\
\hline Adult WrtFQ & -.29 & -.35 & .50 & n.s. & -.19 & & & & & & & & \\
\hline ChildWrt TotFQ & -.32 & -.68 & .71 & .31 & n.s. & .69 & & & & & & & \\
\hline ChildWrt CompFQ & -.33 & -.64 & .68 & .28 & n.s. & .70 & 97 & & & & & & \\
\hline ChildWrt ProdFQ & -.31 & -.72 & .70 & .35 & .10 & .67 & .94 .87 & & & & & & \\
\hline Adult SpkFQ & -.20 & -.26 & .39 & n.s. & -.20 & .69 & .57 & .58 & .56 & & & & \\
\hline NSIZE & -.28 & -.23 & .13 & .13 & n.s. & .16 & 18 & .19 & 20 & n.s. & & & \\
\hline BIGR & n.s. & n.s. & .10 & n.s. & n.s. & .14 & .12 & .11 & .13 & .14 & .23 & & \\
\hline SYL & .35 & .21 & -.10 & n.s. & n.s. & -.22 & -.25 & -.24 & -.26 & n.s. & -.58 & n.s. & \\
\hline LET & .47 & .21 & n.s. & n.s. & n.s. & -.18 & -.22 & -.23 & -.22 & n.s. & -.64 & n.s. & .81 \\
\hline
\end{tabular}

Note-RT, reaction time; AoA, age of acquisition; FAM, familiarity; IMAG, imageability; CONC, concreteness; Adult WrtFQ, adult written word frequency; ChildWrt TotFQ, child written word frequency; ChildWrt CompFQ, frequency of words read by children; ChildWrt ProdFQ, frequency of words written by children; Adult SpkFQ, adult spoken word frequency; NSIZE, number of orthographic neighbors; BIGR, mean bigram frequency; SYL, length in syllables; LET, length in letters. $p<.01$. 
Table 5

Factor Loadings for Predictor Variables (516 Words)

\begin{tabular}{lcccc}
\hline \multicolumn{1}{c}{ Variables } & $\begin{array}{c}\text { Factor 1 } \\
\text { Word Frequency }\end{array}$ & $\begin{array}{c}\text { Factor 2 } \\
\text { Semantics }\end{array}$ & $\begin{array}{c}\text { Factor 3 } \\
\text { Length-NSIZE }\end{array}$ & $\begin{array}{c}\text { Factor 4 } \\
\text { Bigram Frequency }\end{array}$ \\
\hline AoA & -.58 & -.71 & -.14 & -.00 \\
FAM & .71 & .54 & -.01 & .02 \\
IMAG & .12 & .93 & .03 & .01 \\
CONC & -.18 & .82 & .07 & .04 \\
Adult WrtFQ & .86 & -.16 & .13 & .06 \\
ChildWrt CompFQ & .88 & .21 & .15 & -.00 \\
ChildWrt ProdFQ & .87 & .29 & .15 & .01 \\
Adult SpkFQ & .80 & -.23 & -.01 & .11 \\
NSIZE & .07 & .10 & .80 & .28 \\
BIGR & .10 & .03 & .06 & .97 \\
SYL & -.13 & -.03 & -.90 & .14 \\
LET & -.09 & -.04 & -.93 & .00 \\
\% Variance & 31.86 & 21.31 & 20.00 & 8.86 \\
\hline
\end{tabular}

Note-AoA, age of acquisition; FAM, familiarity; IMAG, imageability; CONC, concreteness; Adult WrtFQ, adult written word frequency; ChildWrt CompFQ, frequency of words read by children; ChildWrt ProdFQ, frequency of words written by children; Adult SpkFQ, adult spoken word frequency; NSIZE, number of orthographic neighbors; BIGR, mean bigram frequency; SYL, length in syllables; LET, length in letters.

(3) a length-NSIZE factor (LET, SYL, and NSIZE); (4) a factor including BIGR. The rotated factor analysis accounted for $82.03 \%$ of the variation in the scores. The variance accounted for by each factor is also shown in Table 5.

Multiple regression on factor scores. The four factor scores were used as predictors in a multiple regression analysis, with pronunciation latency as the dependent variable. The present method of regressing the dependent variable on a set of orthogonal factors is a solution to problems of multicollinearity, because all the independent variables (factors) have an intercorrelation of 0.00. A stepwise regression analysis of naming latencies, assessing the contribution of each factor when it was entered into the equation on the last step, was performed. The results of this analysis are presented in Table 6 .

The factor scores altogether accounted for $23.62 \%$ of the variance in naming latencies (multiple $r=.49 ; F=$ $39.51, p<.001$ ). Only two factors contributed significant variance when entered on the last step: The length-NSIZE factor added $14.83 \%(p<.001)$, and the word frequency factor added $8.2 \%(p<.001)$. Neither the semantic factor nor the BIGR factor had any effect on word pronunciation times when the other factors were controlled (for similar results with a subset of 128 picturable words, see also Bates et al., 2001).

\section{GENERAL DISCUSSION}

A main goal of this study consisted in creating a database with lexical and sublexical variables for 626 Italian nouns. Norms for AoA, FAM, IMAG, CONC, various frequency measures, and other lexical and sublexical variables were provided. A classification of lexical stress and of the type of word-initial phoneme was also included. Despite the presence of such an instrument for other languages, this is a new instrument for Italian. The database has a specific utility for research on lexical processing and may provide a useful tool for the study, the assessment, and the rehabilitation of Italian patients with lexical-processing disorders.

A second purpose was to describe the intercorrelations among variables and whether they could be reduced to coherent and distinct factors. Four easily interpretable factors emerged from the analysis: (1) a word frequency factor; (2) a semantic factor; (3) a length-NSIZE factor, and (4) a BIGR factor. Only two variables (i.e., AoA and FAM) loaded on two factors (word frequency and semantics).

A final purpose was to assess which factors are the best predictors of Italian adults' performance in a word-naming task. The results showed that naming latencies are affected primarily by orthographic characteristics of words, such as length and NSIZE, and by different word frequency measures, so that shorter and high-frequency words are read faster than longer and low-frequency words. By contrast, semantic characteristics of words, including IMAG, CONC, and AoA, did not significantly affect word pronunciation times. Neither did a factor defined by BIGR have significant effects on naming times.

These results contribute to exploring the components involved in word naming for a language with shallow orthography, such as Italian. For this language, it is possible, virtually, to read most words aloud without accessing the lexicon, because of the transparent print-to-sound correspondence. And yet word naming does show effects of

Table 6

Regression of Factor Scores on Naming Latencies

\begin{tabular}{lcc}
\hline & $\%$ Variance & $p$ \\
\hline Total (joint variance) & 23.62 & $<.001$ \\
Factor 1: Word frequency & 8.23 & $<.001$ \\
Factor 2: Semantics & 0.50 & n.s. \\
Factor 3: Length and NSIZE & 14.83 & $<.001$ \\
Factor 4: Bigram frequency & 0.09 & n.s. \\
\hline
\end{tabular}


word frequency when other factors are accounted for in a regression design. Nevertheless, the present data from Italian also indicate that semantic effects could be absent when related variables are controlled. This unique contribution from frequency suggests that word naming in Italian does involve lexical access. The presence of frequency effects in the absence of semantic effects contributes to the view that lexical reading aloud is available in Italian, with purely lexical reading aloud dissociable from lexicalsemantic reading (see Burani, Dovetto, Spuntarelli, \& Thornton, 1999; Burani \& Laudanna, in press; see also Bates et al., 2001).

\section{REFERENCES}

ANDREws, S. (1992). Frequency and neighborhoodeffects on lexical access: Lexical similarity or orthographic redundancy? Journal of Experimental Psychology: Language, Memory, \& Cognition, 18, 234-254. ANDREWS, S. (1997). The effect of orthographic similarity on lexical retrieval: Resolving neighborhood conflicts. Psychonomic Bulletin \& Review, 4, 439-461.

Arduino, L. S., \& Burani, C. (2002). Neighborhoodeffects on visual pseudoword processing in a language with shallow orthography. Manuscript submitted for publication.

Baldi, P. L., \& TRaficante, D. (2001).E.P.O.S. Elenco delle parole ortograficamente simili. [E.P.O.S. List of orthographically similar words.] Rome: Carocci.

Balota, D. A., \& Chumbley, J. I. (1985). The locus of word-frequency effects in the pronunciation task: Lexical access and/or production? Journal of Memory \& Language, 24, 89-106.

Balota, D. A., \& Chumbley, J. I. (1990). Where are the effects of frequency on visual word recognition tasks? Right where we said they were! Comment on Monsell, Doyle, \& Haggard (1989). Journal of Experimental Psychology: General, 119, 231-237.

Balota, D. A., Ferraro, F. R., \& Connor, L. T. (1990). On the early influence of meaning in word recognition: A review of the literature. In I. P. Schwanenflugel (Ed.), The psychology of word meaning (pp. 187-221). Hillsdale, NJ: Erlbaum.

Bates, E., Burani, C., D’ Amico, S., \& Barca, L. (2001). Word reading and picture naming in Italian. Memory \& Cognition, 29, 986-999.

Bleasdale, F. A. (1987). Concreteness-dependent associative priming: Separate lexical organization for concrete and abstract words. Journal of Experimental Psychology: Language, Memory, \& Cognition, 13, 582-594.

Brown, G. D. A. (1984). A frequency count of 190,000 words in the London-Lund Corpus of English Conversation. Behavior Research Methods, Instruments, \& Computers, 16, 502-532.

Brown, G. D. A., \& WATSON, F. L. (1987). First in, first out: Word learning age and spoken word frequency as predictors of word familiarity and word naming latency. Memory \& Cognition, 15, 208-216.

Burani, C., BARCA, L., \& ARdUINo, L. S. (2002). Word age-of-acquisition or child written frequency? A new determinant of adult word naming speed. Manuscript submitted for publication.

Burani, C., Dovetto, F. M., Spuntarelli, A., \& Thornton, A. M. (1999). Morpho-lexical access and naming: The semantic interpretability of new root-suffix combinations. Brain \& Language, $\mathbf{6 8}$, 333-339.

Burani, C., \& Laudanna, A. (in press). Morpheme-based lexical reading: Evidence from pseudoword naming. In E. Assink \& D. Sandra (Eds.), Reading complex words. Dordrecht: Kluwer.

Burani, C., Marcolini, S., \& Stella, G. (2002). How early does morpho-lexical reading develop in readers of a shallow orthography? Brain \& Language, 81, 568-586.

Carroll, J. B., Davies, P., \& Richman, B. (1971). Word frequency book. Boston: Houghton Mifflin.

Carroll, J. B., \& White, M. N. (1973). Word frequency and age of acquisition as determiners of picture-naming latency. Quarterly Journal of Experimental Psychology, 25, 85-95.
Cоцомво, L. (1992). Lexical stress effect and its interaction with frequency in word pronunciation. Journal of Experimental Psychology: Human Perception \& Performance, 18, 987-1003.

Colombo, L., \& Burani, C. (2002). The influence of age of acquisition, root frequency and context availability in processing nouns and verbs. Brain \& Language, 81, 398-411.

Colombo, L., \& Tавоssi, P. (1992). Strategies and stress assignment: Evidence from a shallow orthography. In R. Frost \& L. Katz (Eds.), Orthography, phonology, morphology, and meaning (pp. 319-340). Amsterdam: North-Holland.

Coltheart, M. (1981). The MRC psycholinguistic database. Quarterly Journal of Experimental Psychology, 33A, 497-505.

Coltheart, M., Davelaar, E., Jonasson, J. T., \& Besner, D. (1977). Access to the internal lexicon. In S. Dornic (Ed.), Attention and performance VI (pp. 535-555). Hillsdale, NJ: Erlbaum.

Coltheart, V., Laxon, V. J., \& Keating, C. (1988). Effects of word imageability and age of acquisition on children's reading. British Journal of Psychology, 79, 1-12.

Connine, C. M., Mullennix J., Shernoff, E., \& Yelen, J. (1990). Word familiarity and frequency in visual and auditory recognition. Journal of Experimental Psychology: Learning, Memory, \& Cognition, 6, 1084-1096.

CoRNOLDI, C. (1974). Imagery values for 310 Italian nouns. Giornale Italiano di Psicologia/Italian Journal of Psychology, 1, 211-225.

Cortese, M. J., Simpson, G. B., \& Woolsey, S. (1997). Effects of association and imageability on phonological mapping. Psychonomic Bulletin \& Review, 4, 226-231.

Cuetos, F., Ellis, A. W., \& Alvarez, B. (1999). Naming times for the Snodgrass and Vanderwart pictures in Spanish. Behavior Research Methods, Instruments, \& Computers, 31, 650-658.

Dell'Acqua, R., Lotto, L., \& Job, R. (2000). Naming times and standardized norms for the Italian PD/DPSS set of 266 pictures: Direct comparisons with American, English, French, and Spanish published databases. Behavior Research Methods, Instruments, \& Computers, 32, 588-615.

De Mauro, T., Mancini, F., Vedovelli, M., \& Voghera, M. (1993). Lessico di frequenza dell' italiano parlato [Frequency lexicon of spoken Italian]. Milan: ESTALIBRI.

Ellis, A. W., \& Lambon Ralph, M. A. (2000). Age of acquisition effects in adult lexical processing reflect loss of plasticity in maturing systems: Insights from connectionist networks. Journal of Experimental Psychology: Learning, Memory, \& Cognition, 26, 1103-1123.

Ellis, A. W., \& Morrison, C. M. (1998). Real age-of-acquisition effects in lexical retrieval. Journal of Experimental Psychology: Learning, Memory, \& Cognition, 24, 515-523.

Frauenfelder,U. H., BaAyen, R. H, Hellwig, F. M., \& Schreuder, R. (1993). Neighborhood density and frequency across languages and modalities. Journal of Memory \& Language, 32, 781-804.

Frost, R. (1994). Prelexical and postlexical strategies in reading: Evidence from a deep and a shallow orthog raphy. Journal of Experimental Psychology: Learning, Memory, \& Cognition, 20, 116-129.

GERHAND, S., \& BARRY, C. (1998). Word frequency effects in oral reading are not merely age-of-acquisition effects in disguise. Journal of Experimental Psychology: Learning, Memory, \& Cognition, 24, 267-283.

GERHAND, S., \& BARRY, C. (1999). Age of acquisition, word frequency, and the role of phonologyin the lexical decision task. Memory \& Cognition, 27, 592-602.

GERNSBACHER, M. A. (1984). Resolving 20 years of inconsistent interactions between lexical familiarity and orthography, concreteness, and polysemy. Journal of Experimental Psychology: General, 113, 256-281.

Gilhooly, K. J., \& Logie, R. H. (1980). Age-of-acquisition, imagery, concreteness, familiarity, and ambiguity measures for 1,944 words. Behavior Research Methods, Instruments, \& Computers, 12, 395-427.

Gilhooly, K. J., \& Logie, R. H. (1981). Word age-of-acquisition, reading latencies and auditory recognition. Current Psychological Research, 1, 251-262.

Gilhooly, K. J., \& Logie, R. H. (1982). Word age-of-acquisition and lexical decision making. Acta Psychologica, 50, 21-34.

Hudson, P. T. W., \& Bergman, M. W. (1985). Lexical knowledge in word recognition: Word length and word frequency in naming and lexical decision tasks. Journal of Memory \& Language, 24, 46-58. 
Istituto di Linguistica Computazionale, CNR, Pisa, Italy (1989). Corpus di Italiano scritto contemporaneo [Corpus of contemporary written Italian]. Unpublished manuscript.

JAMES, C. T. (1975). The role of semantic information in lexical decisions. Journal of Experimental Psychology: Human Perception \& Performance, 1, 130-136.

Jared, D., \& Seidenberg, M. S. (1990). Naming multisyllabic words. Journal of Experimental Psychology: Human Perception \& Performance, 16, 92-105.

Marconi, L., Ott, M., Pesenti, E., Ratti, D., \& Tavella, M. (1993). Lessico elementare: Dati statistici sull'italiano letto e scritto dai bambini delle elementari [Elementary lexicon: Statistical data for Italian written and spoken by elementary school children]. Bologna: Zanichelli.

Miceli, G., Benveniste, M., Zannino, G. D., \& Capasso, R. (2000). Valori normativi di astrattezza/concretezza di 500 parole italiane [Normative values of abstractness/concreteness for 500 Italian words]. Nuova Rivista di Neurologia, 10, 143-158.

Monsell, S., Doyle, M. C., \& HagGard, P. N. (1989). Effects of frequency on visual word recognition tasks: Where are they? Journal of Experimental Psychology: General, 118, 43-71.

Moore V., \& Valentine T. (1998). The effects of age of acquisition on speed and accuracy of naming famous faces. Quarterly Journal of Experimental Psychology, 51A, 485-513.

Morrison, C. M., \& Ellis, A. W. (1995). Roles of word frequency and age of acquisition in word naming and lexical decision. Journal of Experimental Psychology: Learning, Memory, \& Cognition, 21, 116-133.

Morrison, C. M., \& ElLIS, A. W. (2000). Real age of acquisition effects in word naming and lexical decision. British Journal of Psychology, 91, 167-180

Nisi, M., Longoni, A. M., \& Snodgrass, J. G. (2000). Misure italiane per l'accordo sul nome, familiarità ed età di acquisizione, per 260 figure di Snodgrass e Vanderwart (1980) [Italian norms for name, familiarity, and acquisition age, for the 260 figures of Snodgrass and Vanderwart (1980)]. Giornale Italiano di Psicologia, 27, 205-218.

Noble, C. E. (1953). The meaning-familiarity relationship. Psychological Review, 60, 89-98.

Paivio, A., Clark, J. M., Digdon, N., \& Bons, T. (1989). Referential processing: Reciprocity and correlates of naming and imaging. Memory \& Cognition, 17, 163-174.

Paivio, A., Yuille, J. C., \& Madigan, S. A. (1968). Concreteness, imagery, and meaningfulness values for 925 nouns. Journal of Experimental Psychology Monograph Supplements, 76, (1, Pt. 2), 1-25.

RichARDson, J. T. E. (1975). Imagery, concreteness, and lexical complexity. Quarterly Journal of Experimental Psychology, 27, 211-223.

RINSLAND, H. D. (1945). A basic vocabulary of elementary school children. New York: Macmillan.

Roncato, S. (1974). Concreteness, imagery, meaningfulness and a new index: Values for 100 Italian nouns. Giornale Italiano di Psicologia/ Italian Journal of Psychology, 1, 195-209.

RUBIN, D. C. (1980). 51 properties of 125 words: A unit analysis of verbal behavior. Journal of Verbal Learning \& Verbal Behavior, 19, 736755.

Santiago, J., Justicia, F., Palma, A., Huertas, D., \& Gutiérrez, N. (1996). LEX I and II: Two databases of surface word forms for psycholinguistic research in Spanish. Behavior Research Methods, Instruments, \& Computers, 28, 418-426.

SPIELER, D. H., \& BALOTA, D. A. (1997). Bringing computational models of word naming down to the item level. Psychological Science, $\mathbf{8}$, 411-416.

Spoenr, K. T., \& Smith, E. E. (1973). The role of syllables in perceptual processing. Cognitive Neuropsychology, 5, 71-89.

Strain, E., \& Herdman, C. M. (1999). Imageability effects in word naming: An individual differences analysis. Canadian Journal of Experimental Psychology, 53, 347-359.

Strain, E, Patterson, K., \& Seidenberg, M. S. (1995). Semantic ef- fects in single-word naming. Journal of Experimental Psychology: Learning, Memory, \& Cognition, 21, 1140-1154.

TABossi, P., \& LAGHI, L. (1992). Semantic priming in the pronunciation of words in two writing systems: Italian and English. Memory \& Cog nition, 20, 303-313.

Thornton, A. M., IAcobini, C., \& BURAni, C. (1994). BDVDB: Una base di dati sul vocabolario di base della lingua italiana (1st ed.) [BDVDB: A database on the Italian basic dictionary]. Rome: Istituto di Psicologia del CNR.

Thornton, A. M., Iacobini, C., \& Burani, C. (1997). BDVDB: Una base di dati sul vocabolario di base della lingua italiana [A database on the Italian basic dictionary] (2nd augmented ed.). Rome: Bulzoni. Treiman, R., Mullennix, J., Bijeljac-Babic, R., \& RichmondWELTY, E. D. (1995). The special role of rimes in the description, use, and acquisition of English orthography. Journal of Experimental Psychology: General, 124, 107-136.

Turner, J. E., Valentine, T., \& Ellis, A. W. (1998). Contrasting effects of age of acquisition and word frequency on auditory and visual lexical decision. Memory \& Cognition, 26, 1282-1291.

WEEKES, B. S. (1997). Differential effects of number of letters on word and nonword naming latency. Quarterly Journal of Experimental Psychology, 50A, 439-456.

Whaley, C. P. (1978). Word-nonword classification time. Journal of Verbal Learning \& Verbal Behavior, 17, 143-154.

Yamada, J., TAKashima, H., \& YAmazaKi, M. (1998). Effect of easeof-acquisition on naming latency for Japanese Kanji: A reanalysis of Yamazaki, et al.'s (1997) data. Psychological Reports, 83, 9911002.

Yamazaki, M., Ellis, A. W., Morrison, C. N., \& Lambon Ralph, M. A. (1997). Two age of acquisition effects in the reading of Japanese Kanji. British Journal of Psychology, 88, 407-421.

Zevin, J. D., \& Balota, D. A. (2000). Priming and attentional control of lexical and sublexical pathways during naming. Journal of Experimental Psychology, 26, 121-135

Zingarelli, N. (1985). Il Nuovo Zingarelli: Vocabolario della lingua Italiana [The new Zingarelli dictonary of the Italian language] (11th ed.). Bologna: Zanichelli.

\section{NOTES}

1. We were able to partially check on the reliability of the present ratings by comparing them with those collected by other authors on subsets of overlapping items. There were overlapping items in five other studies in which similar rating instructions were used on a similar population (Italian university students). All the correlation coefficients between the present measures and the measures from the different Italian studies were very high: For AoA, the correlation coefficient was .90 for the subset (128 words) in common with the ratings reported by Bates, Burani, D'Amico, \& Barca (2001); it was .80 for the subset in common (78 words) with Dell'Acqua et al. (2000); and it was .76 for the subset (73 words) in common with Nisi et al. (2000). For IMAG, the correlation coefficient was .79 for the subset ( 74 words) in common with the study by Cornoldi (1974). For CONC, it was .76 (72 common items) with the values reported by Miceli et al. (2000); the coefficient value between our IMAG measures and Miceli et al.'s CONC measures was even higher (.94), presumably on account of the higher similarity in the instructions for the two latter measures. For FAM, we could not check for reliable correlations with existing Italian data, because we had adopted word FAM, whereas other studies (Dell'Acqua et al., 2000; Nisi et al., 2000) had used object FAM. However, the correlation between our word FAM and Dell'Acqua et al.'s object FAM was .33, and it was .43 with Nisi et al.'s object FAM.

2 . We are grateful to the authors of the cited Italian databases for consenting to draw values for the present nouns. Special thanks are due Daniela Traficante, who made the E.P.O.S. database on orthographic neighbors available before publication. 


\section{APPENDIX}

Instructions for Subjective Ratings

\begin{abstract}
Age of acquisition ratings. Instructions
In this study, we need your estimates of the age at which you think you first learned each of a series of words, that is, first learned the word and its meaning, either in spoken or written form. In the following pages you will find a list of words.

\begin{tabular}{ccccccc}
\multicolumn{7}{c}{ learned at the ages of } \\
0-2 & $3-4$ & $5-6$ & $7-8$ & $9-10$ & $11-12$ & $13+$ \\
years & years & years & years & years & years & years \\
1 & 2 & 3 & 4 & 5 & 6 & 7
\end{tabular}
\end{abstract}

Your task is to indicate the age at which you think you learned each word. Rate each word by crossing the number that best indicates the age at which you think you learned that word. If you think you learned a word at the age of 7 years, then you would cross the " 4 " on the scale beside that word; if you think you learned a word at the age of 1 year, then you would cross the " 1 " on the scale beside that word; and so on. Feel free to use all the numbers on the scale and do not be concerned about how often you use a number.

\section{Familiarity ratings. Instructions}

In the following pages, you will find a list of words. Each word has an accompanying scale. The scale ranges from 1 to 7 , as follows:

very little known very well known

$\begin{array}{lllllll}1 & 2 & 3 & 4 & 5 & 6 & 7\end{array}$

Your task is to rate how well you think each word is known by students like you. Rate each word by crossing the number that best indicates your judgment. Keep in mind that the " 1 " corresponds to very little known words, and the " 7 " to the words that you think are very well known by students like you. Use the intermediate numbers for intermediate degrees of knowledge. Feel free to use all the numbers on the scale. Rate each word only once. Remember to rate every word.

\section{Imageability ratings. Instructions}

Words differ in their capacity to arouse mental images of things or events. Some words arouse a sensory experience, such as a mental picture or sound, more quickly and easily than others. In the following pages, you will find a list of words. Each word has an accompanying scale. The scale ranges from 1 to 7 , as follows:

\section{hardly imageable}

highly imageable

$$
\begin{array}{lllllll}
1 & 2 & 3 & 4 & 5 & 6 & 7
\end{array}
$$

Your task is to rate each word. The words that arouse a mental image very quickly and easily should be given a high rating; words that arouse images with the greatest difficulty or not at all should be given a low rating. Feel free to use all the numbers on the scale and do not be concerned about how often you use a number. Rate each word by crossing the number that best indicates your judgment.

\section{Concreteness ratings. Instructions}

The words that refer to objects, living beings, actions, and materials that can be experienced by the senses can be considered as "concrete." Words that refer to concepts that cannot be experienced by the senses can be considered as "abstract." In the following pages, you will find a series of words. Each word has an accompanying scale. The scale ranges from 1 to 7 , as follows:

\section{highly abstract}

highly concrete

$$
\begin{array}{lllllll}
1 & 2 & 3 & 4 & 5 & 6 & 7
\end{array}
$$

Your task is to rate each word for its degree of concreteness or abstractness. Rate each word, considering that the high ratings should be given to concrete words and the low ratings to abstract words. When you rate a word as being neither fully concrete nor fully abstract, give it an intermediate value. Feel free to use all the numbers on the scale and do not be concerned about how often you use a number. Rate each word by crossing the number that best indicates your judgment. 